\title{
OA14.05. Hypnosis for hot flashes: results from a randomized clinical trial and future directions
}

\author{
G Elkins, W Fisher, A Johnson \\ From International Research Congress on Integrative Medicine and Health 2012 \\ Portland, Oregon, USA. 15-18 May 2012
}

\section{Purpose}

Hot flashes are a significant clinical problem for many women. Currently there are limited options to hormone replacement therapy as non-hormonal pharmacological agents are associated with only modest activity and many adverse side effects. Hypnosis is one mind-body therapy that seems particularly promising for treating hot flashes and was investigated in the present study. This study examined the efficacy of hypnosis in reducing both self-reported and physiologically determined hot flash frequency and severity among post-menopausal women.

\section{Methods}

One-hundred and seventy post-menopausal women with moderate to severe hot flashes were randomly assigned to either a 5-session hypnosis intervention or a 5-session structured-attention control condition. All sessions were provided consistent with a treatment manual and all therapists were trained to criteria for consistency and treatment fidelity. Primary outcome measures were selfreported hot flash frequency and severity (determined via daily diaries) and physiologically monitored hot flashes (determined via sternal skin conductance). Physiological assessment of hot flashes were made using 24hour recordings of sternal skin conductance. Measures were obtained at baseline, at the end of the five weeks intervention, and at 12 week follow-up.

\section{Results}

Results demonstrated that hot flash scores (self-report of frequency and severity of hot flashes) for the participants that received the therapist delivered hypnosis intervention decreased by approximately $70 \%$ at 5 weeks and continued to decline to approximately $80 \%$ at the

Baylor University, Waco, USA
12 week follow-up. Physiologically assessed hot flashes demonstrated a $50 \%$ reduction at 5 weeks and approximately $60 \%$ reduction at 12 weeks for participants in the therapist delivered hypnosis condition.

\section{Conclusion}

To our knowledge, this is the first study to demonstrate a clinically significant reduction in physiologically measured hot flashes using a hypnosis intervention. This study has important implications for women experiencing hot flashes who are contraindicated for hormone replacement therapy.

Published: 12 June 2012

\section{doi:10.1186/1472-6882-12-S1-057}

Cite this article as: Elkins et al: OA14.05. Hypnosis for hot flashes: results from a randomized clinical trial and future directions. $B M C$ Complementary and Alternative Medicine 2012 12(Suppl 1):057.

Submit your next manuscript to BioMed Central and take full advantage of:

- Convenient online submission

- Thorough peer review

- No space constraints or color figure charges

- Immediate publication on acceptance

- Inclusion in PubMed, CAS, Scopus and Google Scholar

- Research which is freely available for redistribution 